\title{
Motivation Measurement of an Augmented Reality Traditional Musical Instruments System
}

\author{
Fransiskus Panca JUNIAWAN ${ }^{1 *}$, Dwi Yuny SYLFANIA ${ }^{2}$, Harrizki Arie \\ PRADANA $^{3}$, and Laurentinus LAURENTINUS ${ }^{4}$
}

\author{
Ifransiskus.pj@atmaluhur.ac.id, Department of Computer Science, STMIK Atma Luhur, Jl. Jend. Sudirman, \\ Pangkalpinang, Indonesia \\ ${ }^{2}$ dysylfania@atmaluhur.ac.id, Department of Computer Science, STMIK Atma Luhur, Jl. Jend. Sudirman, \\ Pangkalpinang, Indonesia \\ ${ }^{3}$ harrizkiariep@atmaluhur.ac.id, Department of Computer Science, STMIK Atma Luhur, Jl. Jend. Sudirman, \\ Pangkalpinang, Indonesia \\ ${ }^{4}$ laurentinus@atmaluhur.ac.id, Department of Computer Science, STMIK Atma Luhur, Jl. Jend. Sudirman, \\ Pangkalpinang, Indonesia \\ *Corresponding author: fransiskus.pj@atmaluhur.ac.id
}

\begin{abstract}
The popularity of traditional musical instruments in the eyes of children today has declined. That is due to the development of technology, gadgets, and the internet, which makes them spend more time on it. For this reason, an application that uses Augmented Reality is built to introduce traditional music instruments to them. With the use of technology, interest and motivation expect to get to know and learn conventional musical instruments to grow back. This study aims to measure the extent of the impact that applications have on children as users. Test measurement method uses several variables, namely motivation as a dependent variable. Ease of use, engaging, enjoyment, and usefulness are as independent variables. This study also looks for correlation relationships between the variables used. The results of this study in the form of a hypothesis variable ease of use and engaging have a significant influence on user motivation. Also, variable enjoyment and usefulness do not have a substantial effect on motivation.
\end{abstract}

Keywords: User Experience, motivation, compression, measurement, Augmented Reality

\section{Introduction}

Traditional musical instruments are a legacy that must preserve. Regeneration to children must also be done to keep the culture of traditional musical instruments from being lost. But this is contrary to the facts in the field. In this technological age, children spend more time with gadgets and the internet. With this condition, knowledge and interest in learning traditional musical instruments are reducing. Therefore, the application of Augmented Reality (AR) to the introduction of conventional music instruments is expected to increase the interest of children towards traditional music instruments.

The AR system must be based on User Interface (UI) and User Experience (UX). UX is used to analyze the level of system interaction with users [1]. After the system is built, the next step is to measure the impact of the system. (UX) consists of several variables, one of which is user motivation. The aims is to measure children motivation in using and learning the system.

The system was built based on Android and featured traditional Bangka music instruments. There are many traditional musical instruments in the Bangka area, such as rebab, gong, gambangan, rebanatamborin, caklemong, dambus, and Suling Bangka. The system that was build took four of them, namely dambus, gong, fiddle, and rebanatamborin. The system is built on markers and uses the Vuforia and Unity tools. Figure 1 shows a system built with paper media as its marker.
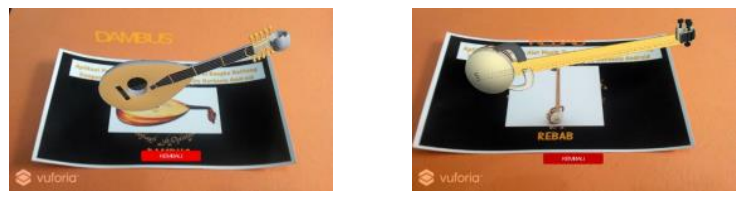

(a)

(b)
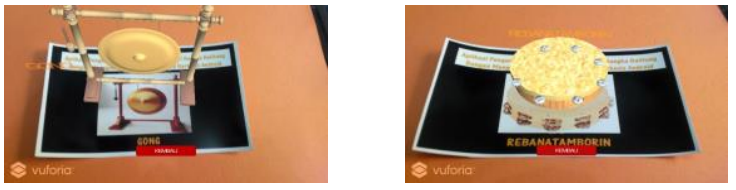

(c)

(d)

Figure 1. Traditional musical instrument AR. a) Dambus; b) Rebab; c) Gong; d) Rebanatamborin

There has been a lot of research with a theme that focuses on the impact and results of $\mathrm{AR}$ on objects. User satisfaction is measured to determine the effect of using Augmented Reality (AR) on the application of speech recognition vocabulary. From the measurement results based on the System Usability Scale (SUS) Score with 80.3 results which means above the average, it stated that the teacher and students are satisfied with the overall application usage [2]. The development of usability 
testing methods in AR applications. Obtained results in the form of developing measurements using the inquiry method by interviewing ten respondents with additional questions. A positive correlation obtained between the interview results and observations on time completion and the number of errors during the performance [3]. In 2016 research was conducted that looked for the advantages and challenges of implementing AR in education based on literature review. The benefits obtained are helping to improve the achievement of student learning. The challenges are usability problems and some technical problems [4]. Next is the use of AR to enhance and engage students in mathematics learning. A survey of learning outcomes is carried out before and after the application of AR. The result is that students can receive knowledge using AR applications and increase their interest in learning [5]. AR is also applied to edutainment applications in the form of mobile games to improve children's enjoyment. Enjoyment assessment is done using user acceptance level evaluation based on gameplay, functionality, and system performance. As many as $67 \%$ of respondents strongly agree that the application enjoys played, $53 \%$ agree that the system runs stable when played, and $67 \%$ agree that the display of information and instructions is clearly stated [6]. The effect of the interrelated Technology Acceptance Model (TAM) on card-based AR applications is to be based on the Perceived Usefulness variable, Perceived Easy to Use, Behavioral Intention Use, and Actual System Use. There is a hypothesis that significant interest in the use of this system is very high [7]. A new model is proposed to find out the level of acceptance of the use of interactive AR technology. This study combines TAM and the experiential value concept that affects sustainable relationship behavior in the use of Augmented Reality Interactive Technology (ARIT). Results in the form of indications that usefulness, ease of use, service excellence, aesthetics, and playfulness are key factors that help the development of sustainable relationship behavior users to use ARIT [8]. AR is also used to increase the involvement of STEM students with authentic curriculum. The results of the study concluded that the level of satisfaction increases, student engagement increases, and a greater awareness of the value of transferable skills [9]. Further research measures the effects of usability problems on learning experiences that enjoy it. The results of the study are four factors that have a strong influence on the issue, namely quality of the screen, ease of reading the information on the screen, the comfort of chemical elements selection, and fatigue [10]. AR is applied to the learning process to increase the value of student attractiveness. This study presents four AR applications to enhance communication and collaboration skills. Besides that, to facilitate learning biology and geography. The results of the study were in the form of four applications to improve student learning activity, especially those with autistic deficiencies [11]. Furthermore, research conducted that applies AR as an educational strategy to enhance the learning process and student motivation. The results of the measurements concluded that there were striking differences in the performance scores and learning motivation of students using the application [12]. Research related to user experience in 2019 conducted experiments on airline e-commerce with the results of five actors that affect airline online applications, namely physical, trust, willingness to learn, context of use and adjustment [13]. There is another study that shows differences in UX values for many product categories. In addition, the cultural impact is much lower than the impact of individual differences of people with the same culture [14].

The purpose of making this system is to increase the interest and motivation of children in re-knowing and learning traditional musical instruments in the Bangka area. For this reason, measurement and testing needed as much as the impact that results from using this application. Sizes use several variables, namely motivation, ease of use, engaging, enjoyment, and usefulness. The results of the test are in the form of a hypothetical correlation relationship between the variables above.

\section{METHOD}

\section{Participants}

The respondents selected from several elementary school students aged between 7-9 years in the City of Pangkalpinang. And then, they would answer the questionnaire given. Nineteen respondents consisted of 10 $(52.63 \%)$ men and $9(47.37 \%)$ women. The method of selecting respondents is random. The author goes directly to the public playground filled with children and asks them directly to request their willingness to use the system. Then, 15-minute trial time given to each child to answers. So they can better understand the use of the system. After the use of the system, questionnaire questions immediately submitted to them.

\section{Measurements}

The application built aims to reintroduce traditional music instruments in Bangka to children. For this goal to achieve, it takes several variables to use as a measure of the extent to which the application can provide a change in children's interest in knowing traditional Bangka music instruments. Motivation is the dependent variable in this study because the essential thing in this study is how to explore children's motivation in knowing conventional musical instruments. Therefore, in the use of this application, the motivation aspect is an important point that must fulfill. That is by the results of previous research, which states that AR applications can increase student motivation in science learning [15]. Besides, there is ease of use, engaging, enjoyable, and usefulness variables used as independent variables. Ease of use is also an advantage in usability challenges in making AR [4]. Appealing and Enhancement is the goal of mathematics learning research using AR [5]. The results of the study showed that AR succeeded in enhancing student mathematics learning. Enjoyment is a variable that wants to improve the implementation of mobile edutainment games. Enjoyment assessment measured from the results of gameplay evaluation, functionality, and performance level with the results, $67 \%$ agrees that the system enjoys being played [6]. Usefulness is an essential variable in the questionnaire results of testing of markerless AR research for demonstration and position of Goddess Nawa Sanga with a value of $88.4 \%$ agree [16]. 


\section{RESULTS}

The research instrument used a questionnaire method consisting of 18 questions and divided into five categories, namely motivation, ease of use, engaging, enjoyment, and usefulness. Questionnaire questions adjusted to previous studies from the Science Motivation Questionnaire II (SMQII) [14]. Likert with a scale of 5 becomes an assessment point on a questionnaire with values (1) being "Strongly Disagree" and (5) is "Strongly Agree".
To do data analysis using descriptive statistical stages, correlation, and regression. Cronbach Alpha values obtained from calculations in Microsoft Excel 2013, shown in Table 1. All Cronbach alpha values have exceeded 0.7 , which means they have met the interrelated and reliable requirements [18].

Table 1. Cronbach Alpha Values

\begin{tabular}{|c|c|c|}
\hline Measurement & Number of Items & Cronbach Alpha $\alpha$ \\
\hline Ease of Use & 4 & 0.754 \\
\hline Engaging & 3 & 0.710 \\
\hline Enjoyment & 3 & 0.834 \\
\hline Motivation & 5 & 0.757 \\
\hline Usefulness & 3 & 0.714 \\
\hline
\end{tabular}

\section{DESCRIPTIVE STATISTIC}

Questionnaire items correspond to the measurement variables, mean, and standard deviations show in Table 2.
The mean for Ease of Use variables is 4.14, for Engaging variables of 4.30, 4.05 for Enjoyment variables, 3.79 for motivation, and 4.02 for Usefulness.

Table 2. Descriptive Statistic

\begin{tabular}{|c|c|c|}
\hline Item & Mean & Std. Deviation \\
\hline Ease of Use & 4.14 & \\
\hline Q1. The system is easy to use & 4.42 & 0.507 \\
\hline Q2. Operation of the system is clear and understandable & 4.05 & 0.780 \\
\hline Q3. The step to use this app is easy to learn & 3.95 & 0.779 \\
\hline Q4. Help menu is helping me to learn how to use this app & 4.16 & 0.688 \\
\hline Engaging & 4.30 & \\
\hline Q5. This app increase my interest to learn traditional musical instrument & 4.42 & 0.692 \\
\hline Q6. This app increases my involvement in art lesson & 4 & 0.882 \\
\hline Q7. This app increases my involvement to studying traditional musical instrument & 4.47 & 0.612 \\
\hline Enjoyment & 4.05 & \\
\hline Q8. It was nice to learn by interacting with traditional musical instrument & 4.16 & 0.602 \\
\hline Q9. I enjoyed using this system & 4.05 & 0.621 \\
\hline Q10. Learning with such a system is entertainment & 3.95 & 0.705 \\
\hline Motivation & 3.79 & \\
\hline Q11. Learning traditional musical instrument is more fun with the use of this app & 3.68 & 0.671 \\
\hline Q12. Increases my motivation to recognize traditional musical instrument. & 4.05 & 0.705 \\
\hline
\end{tabular}




\begin{tabular}{|l|c|c|}
\hline Item & Mean & Std. Deviation \\
\hline Q13. Increases my motivation to learn how to play traditional musical instrument & 3.63 & 0.683 \\
\hline Q14. Increases my motivation to participate in preserving traditional musical instrument & 3.58 & 0.692 \\
\hline Q15. Increases my motivation to share traditional musical instrument & 4 & 0.816 \\
\hline Usefulness & 4.02 & \\
\hline Q16. The use of this app helped me the 3D visualization of traditional musical instrument & 3.84 & 0.602 \\
\hline Q17. Using the system helped me to understanding the shape of traditional musical instrument & 4.32 & 0.582 \\
\hline Q18. 3D visualization of traditional musical instrument help to increase my comprehension & 3.90 & 0.659 \\
\hline
\end{tabular}

\section{CORRELATION}

To measure the correlation value, then the Pearson Correlation Coefficient (r) method used. With the use of statistical evaluations with this method, the relationship between dependent variables (motivation) and independent variables (ease of use, engaging, enjoyment, and usefulness) can measure and know. The correlation value measured between +1 and -1 [16]. Table 3 displays the results of correlation calculations using the Pearson Correlation Coefficient (r) method between all variables. The results of the calculation show that motivation has a positive and significant value towards ease of use, engaging, enjoyment, and usefulness. Sequential values are $.025, .187, .366$, and .074 . All values of the variables are significant at level 0.1 (1-tailed).

Table 3. Pearson Correlation Coefficient Analysis*

\begin{tabular}{|c|c|c|c|c|c|}
\hline Variable & Motivation & Ease of Use & Engaging & Enjoyment & Usefulness \\
\hline Motivation & 1 & & & & \\
\hline Ease of Use & .025 & 1 & & & \\
\hline Engaging & .187 & .121 & 1 & & \\
\hline Enjoyment & .366 & .254 & .333 & 1 & \\
\hline Usefulness & .074 & .117 & .019 & .206 & 1 \\
\hline
\end{tabular}

*) Note: Correlation is significant at the level of 0.1 level (1-tailed)

\section{REGRESSION}

Table 4 displays the results of the regression analysis on the relationship between each variable and to test the hypothesis. The value of R2 is 0.162 , which describes the change in the motivation of respondents regarding the introduction of traditional music instruments. Predictors component in this stage of analysis is independent variables, namely ease of use, engaging, enjoyment, and usefulness. An additional test was also conducted to measure the relationship between each variable to validate the hypothesis. Based on the previous explanation, it known that the acceptable significant $t$-value must be more than 1,645 , and the p-value must be lower than 0.05 [20]. Also calculated is the F ratio according to the ANOVA calculation to determine whether the overall regression model produced is fit to meet the data. Motivation as an independent variable predicts the value for the dependent variable $\mathrm{F}$, which is $(2.47)=47,569$, and the resulting regression model is fit according to the data.

Table 4. Regression Analysis

\begin{tabular}{|l|c|c|c|c|}
\hline Variable & Beta & Standard Error & t-Value & Sig (p-Value) \\
\hline Ease of Use & 0.002 & 0.081 & 2.246 & 0.019 \\
\hline Engaging & 0.072 & 0.100 & 2.944 & 0.002 \\
\hline Enjoyment & 0.121 & 0.087 & 1.659 & 0.053 \\
\hline Usefulness & 0.000 & 0.084 & 1.560 & 0.063 \\
\hline
\end{tabular}




\section{DISCUSSION}

$\mathrm{N}=19$;

R Square $=0.162$

Adjusted $\mathrm{R}^{2}=0.095$

$\mathrm{F}=(2.47)=47.569$
The results of this study also test hypotheses to determine the relationship between Motivation, Ease of use, Engaging, Enjoyment, and Usefulness variables based on regression analysis in Table 4. The results of hypothesis testing presented in Table 5.

Table 5. Hypotheses Testing

\begin{tabular}{|c|c|c|c|}
\hline Hypotheses & Statement & Value & Explanation \\
\hline $\mathrm{H}_{1}$ & Ease of Use variable has a significant effect on motivation & 2.246 & $\begin{array}{l}\mathrm{H}_{1} \text { accepted } \\
\mathrm{H}_{0} \text { rejected }\end{array}$ \\
\hline $\mathrm{H}_{2}$ & Engaging variables have a significant effect on motivation & 2.944 & $\begin{array}{l}\mathrm{H}_{2} \text { accepted } \\
\mathrm{H}_{0} \text { rejected }\end{array}$ \\
\hline $\mathrm{H}_{3}$ & Enjoyment variables have no significant effect on motivation & 1.659 & $\begin{array}{l}\mathrm{H}_{3} \text { rejected } \\
\mathrm{H}_{0} \text { accepted }\end{array}$ \\
\hline $\mathrm{H}_{4}$ & Variable Usefulness has no significant effect on Motivation & 1.560 & $\begin{array}{l}\mathrm{H}_{4} \text { rejected } \\
\mathrm{H}_{0} \text { accepted }\end{array}$ \\
\hline
\end{tabular}

Hypothesis 1 states that there is a significant influence between the Ease variable of use and motivation in the system. This is based on the results of the regression analysis in Table 4 with Beta values $=0.002, \mathrm{t}=2.246$ and $\mathrm{p}=0.019$. Hypothesis 2 states that there is a significant influence between Engaging and Motivation. Table 4 shows the Beta value $=0.072, \mathrm{t}=2.944$ and $\mathrm{p}=$ 0.002 . Hypothesis 3 states that there is no significant influence between the Enjoyment variable and motivation. Based on Table 4, it can be seen that the Enjoyment variable has a Beta value $=0.121, \mathrm{t}=1.659$ and $\mathrm{p}=0.053$. The last is the statement of Hypothesis 4, which states that there is no significant influence between the variable Usefulness and Motivation. This is in accordance with Table 4 which states that the Usefulness variable has a Beta value $=0.000, t=1.560$ and $p=0.063$. Besides, the overall variables correlate positively with Motivation variables, as shown in Table 3. Enjoyment and Usefulness variables that do not have a significant effect should increase so that users can be more motivated in using the system.

\section{CONCLUSION}

Motivation is the biggest challenge in arousing the interest of children to get to know traditional music instruments, especially the Bangka region. With the AR application, it is expected to increase the importance of children to get to know classical music instruments. For this reason, a measurement tool is needed to determine the extent to which the system can increase children's motivation. The variables used are Ease of Use, Engaging, Enjoyment, and Usefulness. From the results of testing the hypothesis, the results show that the Ease of Use and Engaging variables have a significant influence on motivation. Conversely, variable Enjoyment and Usefulness do not have a substantial effect on motivation. Of the two variables that have a considerable impact, it can conclude that AR could be used to attract the interest and motivation of users to get to know music instruments.

These results are following the results of previous studies stating that using AR can help recognize traditional music instruments [18]. AR can also be used to increase motivation in learning something [22]-[11]-[12]. AR can increase engagement [5]-[10]-[9] and also ease of use [7][23]-[8] of motivation.

\section{ACKNOWLEDGMENT}

This research was financially supported by the STMIK Atma Luhur research funding.

\section{REFERENCES}

[1] Roth, R.E, "User Interface and User Experience (UI/UX) Design, "The Geographic Information Science \& Technology Body of Knowledge (2nd Quarter Edition), 2017, https://doi.org/10.22224/gistbok/2017.2.5

[2] N. C. Hashim, N. A. A. Majid, H. Arshad, and W. K. Obeidy, "User Satisfaction for an Augmented Reality Application to Support Productive Vocabulary Using Speech Recognition," Advances in Multimedia, vol. $2018,2018$.

[3] H. Pranoto, C. Tho, H. L. H. S. Warnars, E. Abdurrachman, F. L. Gaol, and B. Soewito, "Usability testing method in Augmented Reality Application," in International Conference on Information Management and Technology (ICIMTech), 2017, no. November, pp. 181-186. 
user experience aspects, "Heliyon Journal, vol. 5, pp. 1-12, 2019. challenges associated with augmented reality for education: A systematic review of the literature," Educational Research Review, vol. 20, pp. 1-11, 2017.

[5] W.-H. Chao and R.-C. Chang, "Using Augmented Reality to Enhance and Engage Students in Learning Mathematics," Advances in Social Sciences Research Journal, vol. 5, no. 12, pp. 455-464, 2019.

[6] O. Y. Beng Keat, N. Wahid, N. Murli, and R. A. Hamid, “Augmented Reality to Induce Enjoyment in Edutainment Mobile Game," JOIV : International Journal on Informatics Visualization, vol. 2, no. 3-2, p. 188, 2018.

[7] D. Yuniarto, M. A. Helmiawan, and E. Firmansyah, "Technology Acceptance in Augmented Reality," JOIN, vol. 3, no. 1, pp. 10-13, 2018.

[8] T. Huang and S. Liao, "A model of acceptance of augmented-reality interactive technology: the moderating role of cognitive innovativeness," Electronic Commerce Research, vol. 15, no. 2, pp. 269-295, 2015.

[9] M. Hobbs and D. Holley, "Using Augmented Reality to Engage STEM Students With an Authentic Curriculum," EL Journal, vol. 3, no. 11, 2016.

[10] C. Pribeanu, "Measuring The Effects of Usability Issues Affecting an Enjoyable Learning Experience A Path Analysis Approach," Journal of Applied Quantitative Methods, vol. 9, no. 3, pp. 14-23, 2014.

[11] A. Iftene and D. Trandab, "Enhancing the Attractiveness of Learning through Augmented Reality," Procedia Computer Science, vol. 126, pp. 166-175, 2018.

[12] J. E. Mat-jizat, H. Jaafar, and R. Yahaya, "Measuring the Effectiveness of Augmented Reality as a Pedagogical Strategy in Enhancing Student Learning and Motivation," International Journal of Academic Research in Business and Social Sciences, vol. 7, no. 1, pp. 225-240, 2017.

[13] S. Pasupa and N. Cheramakara, "Airline Ecommerce User Experience Experiment: An Investigation of Thai LCCs Passengers Purchasing Behaviour among Different Online Platforms, "Journal of Airline and Airport Management, vol. 9, no. 2, pp. 46-55, 2019.

[14] H. B. Santoso and M. Schrepp, "The impact of culture and product on the subjective importance of
[15] J.-C. Yen, C.-H. Tsai, and M. Wu, "Augmented Reality in the Higher Education: Students' Science Concept Learning and Academic Achievement in Astronomy," in Procedia - Social and Behavioral Sciences, 2013, vol. 103, pp. 165-173.

[16] I. W. A. Indrawan, I. P. A. Bayupati, and D. P. Singgih Putri, "Markerless Augmented Reality Utilizing Gyroscope to Demonstrate the Position of Dewata Nawa Sanga," International Journal of Interactive Mobile Technologies (iJIM), vol. 12, no. 1, pp. 19-35, 2018.

[17] S. M. Glynn, P. Brickman, N. Armstrong, and G. Taasoobshirazi, "Science motivation questionnaire II: Validation with science majors and nonscience majors," Journal of Research in Science Teaching, vol. 48, no. 10, pp. 1159-1176, 2011.

[18] J. C. Nunnally, Psychometric theory. New York: McGraw-Hill, 1978.

[19] J. Pallant, SPSS survival manual. New York: McGraw-Hill, 2013.

[20] B. H. Cohen, Explaining Psychological Statistics, 4th ed. New York: John Wiley \& Sons, 2013.

[21] F. P. Juniawan, D. Y. Sylfania, H. A. Pradana, and L. Laurentinus, "Pengenalan alat musik tradisional Bangka dengan Marker-Based Augmented Reality Introduction of traditional Bangka musical instruments with Marker- Based Augmented Reality," Register, vol. 5, no. 34, pp. 89-105, 2019.

[22] T. Khan, K. Johnston, and J. Ophoff, "The Impact of an Augmented Reality Application on Learning Motivation of Students," Advanced Human-Computer Interaction, vol. 2019, no. 1, pp. 1-14, 2019.

[23] F. Wild, R. Klemke, P. Lefrere, M. Fominykh, and T. Kuula, "Technology Acceptance of Augmented Reality and Wearable Technologies Introduction," in International Conference on Immersive Learning, 2017, June. 